\title{
Statement on Minimum Standards for the Care of Older People in Emergency Departments by the Geriatric Emergency Medicine Special Interest Group of the International Federation for Emergency Medicine - ERRATUM
}

Brittany Ellis; Christopher R. Carpenter; Judy A. Lowthian; Simon P. Mooijaart; Christian H. Nickel; Don Melady

doi: $\underline{10.1017 / \mathrm{cem} .2017 .426}$

In the original publication of this article, several authors (Carpenter, Lowthian, Mooijaart, and Nickel) were missing their middle initials. For indexing purposes, these have been updated in the original.

As well, there was a misspelling in one of Lowthian's affiliations. The correct affiliation is as follows:

\section{REFERENCE}

Ellis B, Carpenter CR, Lowthian JA, et al. Statement on Minimum Standards for the Care of Older People in Emergency Departments by the Geriatric Emergency Medicine Special Interest Group of the International Federation for Emergency Medicine. CFEM 2018; epub, doi:10.1017/ cem.2017.426.

§School of Public Health \& Preventive Medicine, Monash University, Melbourne, Australia.

The publisher regrets these errors. 